\title{
The Effects of Surgical Myectomy on Left Ventricular Mechanics in Patients with Hypertrophic Obstructive Cardiomyopathy
}

Abd-El-Kareem TS ${ }^{1^{*}}$, Mohamad $\mathrm{A}^{2}$, Ibrahim $\mathrm{Y}^{2}$, Badran $\mathrm{HM}^{3}, \mathrm{Al}^{3}$-Amin $\mathrm{AM}^{1}$ and Ahmed NF ${ }^{3}$

${ }^{1}$ Faculty of Medicine, Department of Cardiology, Al-Azhar University, Egypt

${ }^{2}$ Cardiology Unit, Al-Azhar University, Cairo, Egypt

${ }^{3}$ Faculty of Medicine, Department of Cardiology, Menofia University, Egypt

*Corresponding author: Abd-El-Kareem TS, Faculty of Medicine, Department of Cardiology, Al-Azhar University, 32511, Cairo, Egypt, Tel: + 01126570704; E-mail: Tahersalman2013@yahoo.com

Received: December 09, 2018; Accepted: January 21, 2019; Published: January 25, 2019

Copyright: (c) 2018 Abd-El-Kareem TS, et al. This is an open-access article distributed under the terms of the creative commons attribution license, which permits unrestricted use, distribution, and reproduction in any medium, provided the original author and source are credited.

\begin{abstract}
Background: Hypertrophic obstructive cardiomyopathy (HOCM) is an inherited disorder, characterized by left ventricle outflow tract obstruction. We performed this study to investigate the changes in left ventricular mechanics after surgical myectomy in patients with HOCM.
\end{abstract}

Materials and methods: We enrolled 15 patients with HOCM referred to surgical myectomy according to the recommendation of American Heart Association. All patients underwent transthoracic 2D speckle-tracking echocardiography to measure cardiac dimensions and mechanics before and after surgery. statistical analyses were performed using GraphPad Instat and MedCalc software.

Results: Following myectomy, all patients reported improved symptoms and increased functional capacity. Conventional echocardiographic measurements showed that surgical myectomy significantly decreased left atrial volume index $(r=0.83, p<0.0001)$, interventricular septum thickness $(p<0.0001, r=0.79)$, left-ventricular mass index $(p<0.0001, r=0.49)$ and resting left-ventricular outflow tract pressure gradient $(p<0.0001, r=-0.03)$. In terms of leftventricular function, we observed significant decreases in fractional shortening $(r=0.16, p<0.0001)$ and ejection fraction $(p=0.01, r=-0.04)$ after the procedure in comparison to baseline functional data. We further significant postoperative reductions in terms of average circumferential strain $(p<0.0001, r=0.49)$, basal rotation $(p=0.03$, $r=0.97)$, apical rotation $(p<0.0001, r=0.94)$ and LV twist $(p<0.0001, r=0.96)$. However, no significant changes were observed after myectomy in terms of most longitudinal strain and left ventricular synchrony measures.

Conclusion: Surgical myectomy improves symptoms, relieves left ventricular outflow tract obstruction and decreases left atrial volume index in patients with HOCM, but shows no significant changes in LV longitudinal strain and LV synchrony measures. Future studies should employ a larger sample size and more sensitive methods of synchrony detection.

Keywords: Cardiomyopathy; Echocardiography; Hypertrophic; Myectomy

Abbreviations: AS: Aortic Stenosis; HOCM: Hypertrophic Obstructive Cardiomyopathy; TTP: Time to Peak

\section{Introduction}

Hypertrophic obstructive cardiomyopathy (HOCM) is a common, inherited myocardial disorder that affects $1 / 500$ adults in the general population [1]. The main genetic abnormality, associated with HCM is mutation in the sarcomeric protein genes, which lead to myocardial cells' disarray and fibrosis in the entire myocardium [2]. Pathologically, it is characterized by left ventricular outflow tract obstruction, induced by thickening of the interventricular septum and systolic anterior motion of the mitral valve [3]. Its complications may include heart failure, stroke and sudden cardiac death [2]. Several therapeutic strategies were developed to diminish the outflow tract obstruction by reducing the interventricular septum width [4]. Invasive interventions are usually considered in HOCM management when medications fail to control the symptoms or are not tolerated. These interventions include dual-chamber permanent pacing, septal ethanol ablation and surgical myectomy [5-7]. The latter option is regarded as the most efficient approach to ameliorate the obstruction and relive associated mitral regurgitation by removing the protruding parts of the myocardium. Moreover, it provides acceptable quality of life at any age, exceeding that achievable with long-term administration of cardioactive drugs [8]. As a response to the increased afterload in aortic stenosis (AS), several compensatory mechanisms occur, such as left ventricular hypertrophy, reduction of the longitudinal strain, increased circumferential strain and increased left ventricular twist. These mechanisms are often relieved by aortic valve replacement $[9,10]$. Although similar events occur in HOCM patients, there are limited data about the effects of surgical myomectomy on such compensatory mechanisms. In this study, we investigated the changes in left ventricular mechanics after surgical myectomy in patients with HOCM.

\section{Materials and Methods}

This study included 15 patients with hypertrophic obstructive cardiomyopathy refractory to medical treatment referred to surgical myectomy according to the recommendation of American Heart 
Association. They were examined in a single centre (Yacoub Research Unite, Menoufia University, Egypt). Patients were enrolled in the study after their informed consent and approval of Ethics Committee of Menoufia University Hospitals was obtained from August 2011 to August 2016.

We included patients with Hypertrophic obstructive cardiomyopathy (HOCM) and drug refractory symptoms: dyspnea [NYHA functional class III-IV], angina pectoris [Canadian Cardiovascular Society class III-IV] or syncope. All patients had a LV outflow tract pressure gradient $>50 \mathrm{mmHg}$ at rest or after provocation. We excluded patients who had 1) poor echo window, 2) clinical or echocardiographic evidence of other cardiac diseases such as pericardial or congenital heart disease and 3) NYHA functional class IV.

All patients were subjected to the following measures before and within six months after myectomy: full history taking to assess severity of symptoms and medication used, full clinical examination, resting 12 lead ECG, transthoracic echo-Doppler study. The examination was done using Esaote (My Lab 30 Gold machine; Esaote My lab Gold ultrasound system; Esaote S.p.A, Florence, Italy), equipped with a 5 $\mathrm{MHz}$ phased-array transducer. The following data were obtained:

a) Using 2D and 2D guided M-mode to assess: LV end-systolic and end-diastolic dimensions $\left(\mathrm{mm}^{2}\right)$, LV ejection fraction (\%), fractional shortening (\%), interventricular septum end-diastolic diameter ( $\mathrm{mm})$, $\mathrm{LV}$ posterior wall end-diastolic diameter $(\mathrm{mm})$ and Septum/Posterior wall Ratio, left atrial dimension $(\mathrm{mm})$, volume $(\mathrm{ml})$ and volume index, LV mass ( $\mathrm{g}$ ) and LV mass index.

b) Using Convention Doppler Echo to assess: Max Resting LV outflow tract pressure gradient, presence or absence of mitral regurgitation and it's Degree, Mitral E and A wave Velocities $(\mathrm{cm} / \mathrm{s})$, $\mathrm{E} / \mathrm{A}$ Ratio and estimated systolic pulmonary artery pressure $(\mathrm{mmHg})$.

c) Using Tissue Doppler imaging to assess: S velocity, Ea velocity, Aa Velocity and E/Ea Ratio (before and after surgical myectomy).

\section{Two-dimensional speckle tracking}

For the assessment of LV circumferential strain, three LV short-axis planes were acquired at the basal, middle, and apical levels of the LV at high frame rates (range: 67-92 frame(s); mean $81+5$ frame(s)). Care was taken to ensure that the basal short-axis views were obtained at the level of the mitral valve, the middle planes at the level of the papillary muscles, and apical planes distal to the papillary muscles. For longitudinal strain assessment, three LV apical views, apical fourchamber, two chamber, and long-axis views were acquired at high frame rates (range: 59-82 frame(s); mean $72+6$ frame(s)). In each plane, three consecutive cardiac cycles were acquired during a breath hold and digitally stored in a hard disk for off-line analysis. In order to measure the timing of cardiac events, LV inflow and outflow velocities were recorded using pulsed-wave Doppler echocardiography.

\section{Analysis of myocardial mechanics}

The following data were obtained

a) Baseline (preprocedural) and follow-up strain measurements were performed using 2D tissue-tracking software (Velocity Vector Imaging version 3.0.0; Esaote Medical Solutions, Italy). b) From archived 2D echocardiographic studies, Longitudinal wall strain and strain rate were averaged from 17-segment measurements from the apical two-chamber, three-chamber, and four-chamber views.

c) Circumferential strain, strain rate, and rotation velocities and angles were measured in six segments per short-axis plane (at the basal and mid-ventricular papillary muscle LV level) and in four segments at the apical level. Measurements were averaged for each short-axis level.

d) Averaged myocardial rotation angles were used to calculate the basal-apical LV twist, defined as the maximal instantaneous mid-to apical rotation angle difference.

e) LV dyssynchrony was defined as the standard deviation of the averaged time-to-peak-strain (TPS-SD). A value $>60 \mathrm{~ms}$ for TPS-SD was used to define significant LV dyssynchrony.

\section{Mechanics analysis reproducibility assessment}

Intra-observer agreement intra-class correlation coefficients were 0.92 for strain ( $95 \%$ CI, $0.85-0.96$ ), and 0.97 for peak rotation angle (95\% CI, 0.95-0.99). Inter-observer intra-class correlation coefficients were somewhat lower, at 0.88 for strain $(95 \% \mathrm{CI}, 0.74-0.96)$ and 0.87 for peak rotation angle ( $95 \% \mathrm{CI}, 0.64-0.97)$. There was $100 \%$ agreement between observers regarding rotation direction. The data (Pre and within 6 months after myectomy) were compared to assess (a) effect of myectomy on the patient's functional status and (b) effect of myectomy on myocardial mechanics.

\section{Statistical Analysis}

Statistical analyses were performed using GraphPad Instat and MedCalc software. Data were expressed as mean \pm standard deviations (SD). We employed the Wilcoxon sign test for paired data to determine the significance of differences before and after surgical myectomy. Results were considered significant if $\mathrm{p}<0.05$ and highly significant if $p$-value $<0.01$. To test the relationship between different variables, the Spearman's rank correlation analysis was performed. Moreover, the forward stepwise regression was performed to determine predictors of LV dyssynchrony. A value $>60 \mathrm{~ms}$ for TPS-SD was used to define HOCM with LV dyssynchrony.

\section{Results}

\section{Baseline data}

Surgical myectomy was successfully performed in all 15 patients (eight cases did myectomy in Magdy Yacoub Cardiology Center, Two cases in Ain Shams Cardiology Academy, one case in National Heart Institute and four cases in private hospitals) between August 2011 and August 2016. The mean age of enrolled patients was 33.5 years and the mean follow-up duration was 12.1 months. The baseline characteristics of enrolled patients are summarized in Table 1.

\section{Conventional echo Doppler measurements}

Comparison of changes in Conventional Echo variables showed that after surgical myectomy there were a significant decrease in left atrial dimension $(r=0.81, p<0.0001)$, left atrial volume $(r=0.92, p<0.0001)$, and left atrial volume index $(\mathrm{r}=0.83, \mathrm{p}<0.0001)$, compared to preoperative recordings. On the other hand, we recorded a significant increase in left-ventricular systolic dimension after surgery $(r=0.46$, $\mathrm{p}<0.0001$ ); however, no significant change was recorded in left 
Citation: Abd-El-Kareem TS, Badran HM, Al-Amin AM, Ahmed NF (2019) The Effects of Surgical Myectomy on Left Ventricular Mechanics in Patients with Hypertrophic Obstructive Cardiomyopathy. J Cardiovasc Dis Diagn 7: 356. doi:10.4172/2329-9517.1000356

Page 3 of 7

ventricular diastolic dimension between both time points $(r=0.63$, $\mathrm{p}=0.11)$. In terms of left-ventricular function, we observed significant decreases in fractional shortening $(\mathrm{r}=0.16, \mathrm{p}<0.0001)$ and ejection fraction $(\mathrm{p}=0.01, \mathrm{r}=-0.04)$ after the procedure in comparison to baseline functional data.

\begin{tabular}{|l|l|}
\hline Items & Patients (n=15) \\
\hline Age (yrs) & $33.5 \pm 10.3$ \\
\hline Male Sex, $n$ (\%) & $9,60 \%$ \\
\hline Body Surface Area (m²) & $1.8 \pm 0.12$ \\
\hline NYHA class III, $n$ (\%) & $15,100 \%$ \\
\hline Familial HCM, $n$ (\%) & $2,13.3 \%$ \\
\hline Type of LVH, $n$ (\%) & $14,93.3 \%$ \\
\hline A Symmetrical & $1,6.7 \%$ \\
\hline Localized (Basal septum) & \multicolumn{2}{|l|}{} \\
\hline Symptoms, $n$ (\%) & $\begin{array}{l}13,86.7 \% \\
1,6.7 \%\end{array}$ \\
\hline $\begin{array}{l}\text { Exertional dyspnea } \\
\pm \text { Exertional chest pain } \\
\pm \text { Fever }\end{array}$ & $1,6.7 \%$ \\
\hline HR (b/m) & $67.3 \pm 10.47$ \\
\hline SBP (mmHg) & $115.7 \pm 7.76$ \\
\hline DBP (mmHg) & $73.33 \pm 4.08$ \\
\hline $\begin{array}{l}\text { Medications } \\
\text { BB + CCB } \\
\text { BB alone } \\
\text { BB + antibiotics }\end{array}$ & $\begin{array}{l}13,86.7 \% \\
1,6.7 \%\end{array}$ \\
\hline Follow up duration (months) & $12.07 \pm 8.3$ \\
\hline $\begin{array}{l}\text { Note: BB (Beta blockers), CCB (calcium channel blockers), Data are means } \pm \\
\text { standard deviations unless otherwise indicated. }\end{array}$ \\
\hline
\end{tabular}

Table 1: Summary of baseline characteristics of enrolled patients.

In addition, our analysis showed significant decreases in interventricular septum thickness $(\mathrm{p}<0.0001, \mathrm{r}=0.79)$, septum/ posterior wall ratio $(\mathrm{p}=0.009, \mathrm{r}=0.62)$, left-ventricular mass index $(\mathrm{p}<0.0001, \mathrm{r}=0.49)$ after the procedure. Further, we recorded significant decreases in resting $\mathrm{LV}$ outflow tract pressure gradient $(\mathrm{p}<0.0001, \mathrm{r}=-0.03), \mathrm{E} / \mathrm{E}^{\prime}$ ratio $(\mathrm{p}<0.0001, \mathrm{r}=-0.08)$, as well as a significant increase in $\mathrm{E}^{\prime}$ velocity of the basal segment of the lateral wall $(\mathrm{p}<0.0001, \mathrm{r}=0.22)$ after surgical myectomy, compared to preoperative measurements (Figures 1-4). The conventional Echo Doppler characteristics before and after surgical myectomy are summarized in Table 2.

\section{Cardiac Mechanics}

Longitudinal strain: The 2D speckle tracking of Longitudinal strain (Esys \%) descriptives pre and post-surgical myectomy in enrolled patients are summarized in Table 3. Our analysis showed no significant changes between preoperative and postoperative measurements in terms of the mean value of $£$ sys $\%$ of the septum $(\mathrm{p}=0.18, \mathrm{r}=-0.19)$, mean value of $£$ sys $\%$ of the lateral wall ( $\mathrm{p}=0.27, \mathrm{r}=0.48)$, mean value of Esys \% of the anterior wall ( $\mathrm{p}=0.49, \mathrm{r}=0.48)$, mean value of $\mathfrak{E}$ sys $\%$ of the inferior wall $(\mathrm{p}=0.153, \mathrm{r}=0.346)$, the mean value of the $4 \mathrm{CH} £$ sys \% $(\mathrm{p}=0.23, \mathrm{r}=-0.05)$, the mean value of $2 \mathrm{CH} \mathfrak{E}$ sys $\%(\mathrm{p}=0.91, \mathrm{r}=-0.02)$ and the mean value of global LV £sys \% ( $\mathrm{p}=0.15, \mathrm{r}=0.14)$. However, a significant increase in $\mathfrak{E}$ sys \% of the Basal inferior myocardial segment ( $\mathrm{p}=0.03, \mathrm{r}=0.45$ ), as well as a significant decrease in $£$ sys \% the Basal septum $(\mathrm{p}=0.004, \mathrm{r}=0.12)$ were recorded after surgical myectomy.

\begin{tabular}{|c|c|c|c|}
\hline Items & Pre Myectomy & Post Myectomy & p Value \\
\hline LA diameter (mm) & $46.53 \pm 9.23$ & $37.6 \pm 4.54$ & 0.0001 \\
\hline LA volume (ml) & $69.47 \pm 11.39$ & $48.83 \pm 6.21$ & 0.0001 \\
\hline $\mathrm{LA}$ volume index $\left(\mathrm{cm}^{3} / \mathrm{m}^{2}\right)$ & $37.8 \pm 5.61$ & $26.38 \pm 3.37$ & 0.0001 \\
\hline LV End-systolic diameter & $21.8 \pm 4.0$ & $26.53 \pm 3.16$ & 0.003 \\
\hline LV End-diastolic diameter & $40.67 \pm 6.1$ & $43.06 \pm 6.77$ & 0.114 \\
\hline Fractional shortening (\%) & $47.93 \pm 9.16$ & $36.8 \pm 3.62$ & 0.0001 \\
\hline Ejection fraction (\%) & $74.27 \pm 8.83$ & $66.8 \pm 3.70$ & 0.01 \\
\hline Septal thickness (mm) & $25.73 \pm 5.45$ & $19.93 \pm 4.44$ & 0.0001 \\
\hline LV posterior wall (mm) & $10.49 \pm 1.24$ & $9.82 \pm 1.29$ & 0.086 \\
\hline Septum/posterior wall ratio & $2.5 \pm 0.64$ & $2.04 \pm 0.67$ & 0.009 \\
\hline LV Mass (g) & $438.53 \pm 85.04$ & $294.53 \pm 69.17$ & 0.0001 \\
\hline LV Mass index & $242.78 \pm 47.45$ & $166 \pm 47.65$ & 0.0001 \\
\hline $\begin{array}{l}\text { LV Outflow tract pressure } \\
\text { gradient }(\mathrm{mmHg})\end{array}$ & $63.13 \pm 10.25$ & $9.96 \pm 2.72$ & 0.0001 \\
\hline Mitral E $(\mathrm{cm} / \mathrm{s})$ & $74.33 \pm 12.34$ & $66.26 \pm 14.26$ & 0.073 \\
\hline Mitral A $(\mathrm{cm} / \mathrm{s})$ & $67.27 \pm 15.06$ & $62.66 \pm 13.12$ & 0.425 \\
\hline Mitral E/A & $1.14 \pm 0.29$ & $1.07 \pm 0.26$ & 0.574 \\
\hline DT (msec) & $188.47 \pm 14.67$ & $199.33 \pm 22.16$ & 0.128 \\
\hline $\mathrm{PAP}(\mathrm{mmHg})$ & $26.33 \pm 2.84$ & $26.4 \pm 2.32$ & 0.93 \\
\hline $\mathrm{Sm}(\mathrm{cm} / \mathrm{sec})$ & $8.73 \pm 1.87$ & $10.2 \pm 1.52$ & 0.006 \\
\hline $\mathrm{Em}(\mathrm{cm} / \mathrm{sec})$ & $5 \pm 1.19$ & $7.2 \pm 1.08$ & 0.0001 \\
\hline $\mathrm{Am}(\mathrm{cm} / \mathrm{sec})$ & $9.07 \pm 1.83$ & $10.26 \pm 1.09$ & 0.021 \\
\hline $\mathrm{E} / \mathrm{Ea}$ & $15.23 \pm 2.39$ & $9.18 \pm 1.42$ & 0.0001 \\
\hline
\end{tabular}

Note: Data are means \pm standard deviations.

Table 2: Summary of conventional echo characteristics before and after myectomy.

Circumferential strain, basal rotation, apical rotation and LV twist: The 2D speckle tracking descriptives (as regard circumferential strain [\%], apical, basal rotation and LV twist) pre and post-surgical myectomy are summarized in Table 4 . In brief, we recorded significant postoperative reductions in terms of average circumferential strain $(\mathrm{p}<0.0001, \mathrm{r}=0.49)$, basal rotation $(\mathrm{p}=0.03, \mathrm{r}=0.97)$, apical rotation $(\mathrm{p}<0.0001, \quad \mathrm{r}=0.94)$ and LV twist $(\mathrm{p}<0.0001, \quad \mathrm{r}=0.96)$. Echocardiographic images of longitudinal and circumferential strain in different segments before and after surgical myectomy are illustrated in Figures 1-4. 
Citation: Abd-El-Kareem TS, Badran HM, Al-Amin AM, Ahmed NF (2019) The Effects of Surgical Myectomy on Left Ventricular Mechanics in Patients with Hypertrophic Obstructive Cardiomyopathy. J Cardiovasc Dis Diagn 7: 356. doi:10.4172/2329-9517.1000356

Page 4 of 7

\begin{tabular}{|l|l|l|l|}
\hline Items & Pre Myectomy & Post Myectomy & p value \\
\hline £sys \% Basal sept & $-7.40 \pm 2.2$ & $-5.06 \pm 1.75$ & 0.004 \\
\hline £sys\% Mid sept & $-8.33 \pm 2.9$ & $-8.00 \pm 2.77$ & 0.765 \\
\hline $\begin{array}{l}\text { £sys \% Apical } \\
\text { sept }\end{array}$ & $-10.27 \pm 3.1$ & $-9.46 \pm 3.04$ & 0.535 \\
\hline $\begin{array}{l}\text { £sys septum } \\
\text { Mean }\end{array}$ & $-8.66 \pm 1.95$ & $-7.51 \pm 2.20$ & 0.188 \\
\hline £sys\% basal lat & $-9.87 \pm 3.96$ & $-11.80 \pm 3.46$ & 0.085 \\
\hline £sys\% Mid lat & $-8.67 \pm 3.39$ & $-9.00 \pm 3.60$ & 0.731 \\
\hline £sys\% Apical Lat & $-8.40 \pm 3.11$ & $-8.73 \pm 2.96$ & 0.719 \\
\hline £sys\% lat Mean & $-8.97 \pm 2.75$ & $-9.84 \pm 2.95$ & 0.269 \\
\hline £sys\% Basal ant & $-10.20 \pm 2.88$ & $-9.26 \pm 2.40$ & 0.182 \\
\hline £sys\% Mid ant & $-9.93 \pm 3.17$ & $-8.53 \pm 3.02$ & 0.181 \\
\hline £sys\% Apical ant & $-8.00 \pm 3.02$ & $-9.13 \pm 3.31$ & 0.339 \\
\hline £sys\% Ant Mean & $-9.38 \pm 1.95$ & $-8.97 \pm 2.43$ & 0.497 \\
\hline £sys\% Basal inf & $7.73 \pm 3.15$ & $-9.60 \pm 2.52$ & 0.031 \\
\hline £sys\% Mid inf & $-8.73 \pm 2.05$ & $-9.33 \pm 2.19$ & 0.486 \\
\hline £sys\% Apical inf & $-9.67 \pm 2.89$ & $-9.73 \pm 2.46$ & 0.94 \\
\hline £sys\% Mean inf & $-8.71 \pm 2.13$ & $-9.55 \pm 1.53$ & 0.153 \\
\hline $\begin{array}{l}\text { G CH £sys \% LV } \\
\text { Glob }\end{array}$ & $-6.43 \pm 6.54$ & $-8.70 \pm 2.30$ & 0.232 \\
\hline $\begin{array}{l}\text { 2 CH £sys \% } \\
\text { global }\end{array}$ & $-8.00 \pm 4.57$ & $-7.78 \pm 5.48$ & 0.911 \\
\hline £sys\% LV Global & $-6.45 \pm 6.59$ & $-9.00 \pm 1.66$ & 0.155 \\
\hline Note: Data are means & & \\
\hline
\end{tabular}

$\max (\mathrm{p}=0.24, \mathrm{r}=0.32)$ and TTP-d $(\mathrm{p}=0.305, \mathrm{r}=0.28)$. However, we noted a significant decrease in TTP min after surgical myectomy compared to initial measurement $(\mathrm{p}=0.01, \mathrm{r}=0.64)$.
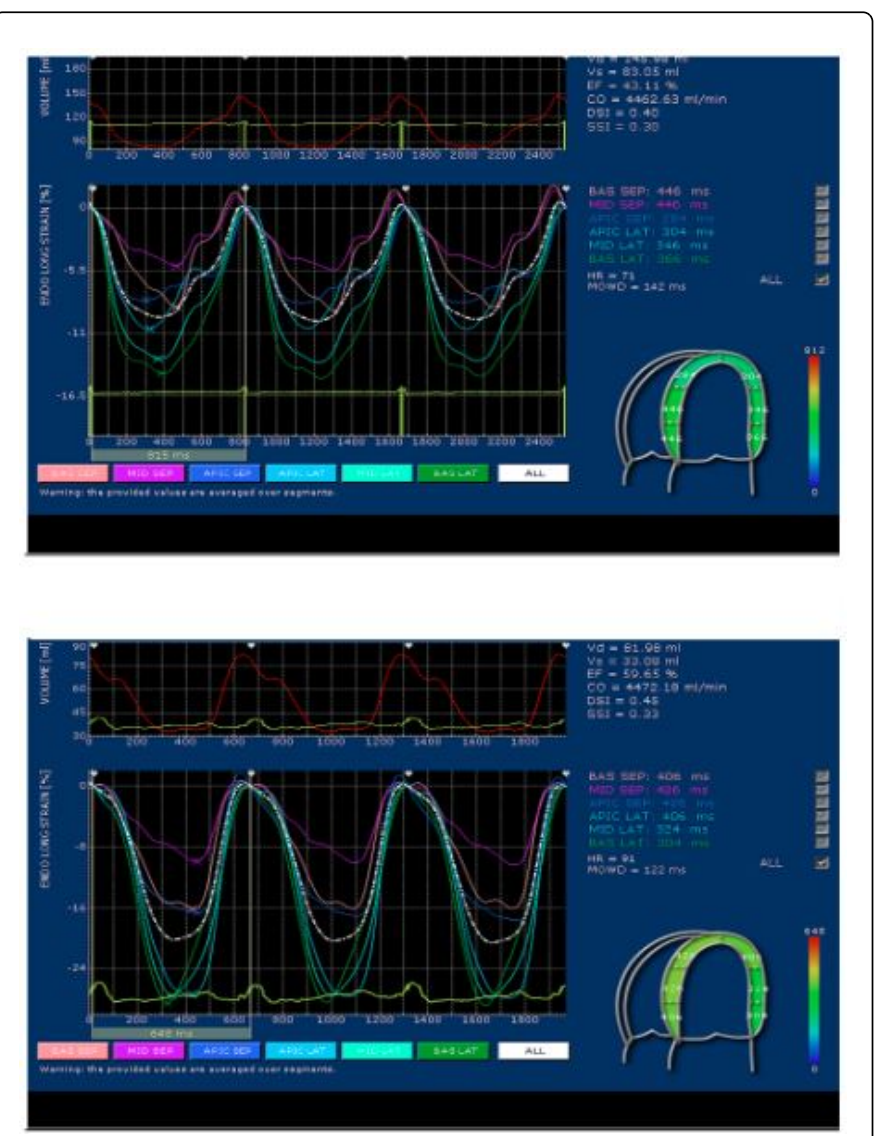

Note: Data are means \pm standard deviations

Table 3: Summary of 2D ST (LS) descriptives pre and post myectomy of study populations.

\begin{tabular}{|l|l|l|l|}
\hline Items & Pre Myectomy & Post Myectomy & p-value \\
\hline Circ Strain $(\%)$ & $-28.47 \pm 3.35$ & $-18.26 \pm 2.86$ & $<0.0001$ \\
\hline Basal rotation $\left(^{\circ}\right)$ & $-8.59 \pm 1.51$ & $-7.82 \pm 1.47$ & $\leq 0.03$ \\
\hline Apical rotation $\left(^{\circ}\right)$ & $11.12 \pm 1.87$ & $8.17 \pm 1.88$ & $<0.0001$ \\
\hline Twist & $16.52 \pm 2.25$ & $14.02 \pm 1.21$ & $<0.0001$ \\
\hline
\end{tabular}

Note: Data are means \pm standard deviations.

Table 4: Summary of 2D ST (CS, Apical, basal Rotation, and LV twist) descriptives pre and post myectomy of study populations.

LV synchronization: The $2 \mathrm{D}$ speckle tracking descriptive of time to peak (TTP) pre and post-surgical myectomy are summarized in Table 5. No significant changes were recorded between preoperative and postoperative measurements in terms of TTP of the septum $(\mathrm{p}=0.57$, $\mathrm{r}=-0.15)$, TTP of the lateral wall $(\mathrm{p}=0.1, \mathrm{r}=0.41)$, TTP of the anterior wall $(\mathrm{p}=0.26, \mathrm{r}=0.306)$, TTP of the inferior wall $(\mathrm{p}=0.51, \mathrm{r}=0.18)$, TTPSD $(\mathrm{p}=0.49, \mathrm{r}=0.19)$, TTP mean of global LV $(\mathrm{p}=0.05, \mathrm{r}=0.51)$, TTP

Figure 1: Longitudinal strain of septal and lateral wall segments before (upper panel) and after (lower panel) surgical myectomy of the same patient.

\section{Discussion}

We conducted this study to characterize the impact of surgical myectomy on LV mechanics in HOCM patients. Our study demonstrated marked reduction of left atrial diameter, volume and volume index after surgical myectomy, mostly due to decrease of the grade of mitral regurgitation and diastolic function with subsequent decrease in left atrial pressure. Similar results were obtained by Moravsky et al., and Carasso et al., after surgical myectomy and aortic valve replacement $[11,12]$. In contrast to Moravsky et al. who reported symptomatic and functional improvement in only $70 \%$ of enrolled patients after myectomy [11], we noticed such improvement in all our patients. This discordance may be due to the smaller sample size or the younger patients' age in our study.

Moreover, we recorded a significant decrease in the longitudinal strain of the basal septum (which is the main site of myectomy) after surgery. This is concordant with Moravsky et al. on surgical myectomy patients [11], but discordant with the results of Faber et al. who reported no significant change in basal septum longitudinal strain after alcohol septal ablation (which does not include removing parts of the myocardium) [13]. There was a non-significant increase in global LV 
Citation: Abd-El-Kareem TS, Badran HM, Al-Amin AM, Ahmed NF (2019) The Effects of Surgical Myectomy on Left Ventricular Mechanics in Patients with Hypertrophic Obstructive Cardiomyopathy. J Cardiovasc Dis Diagn 7: 356. doi:10.4172/2329-9517.1000356

Page 5 of 7

longitudinal strain after surgical myectomy. This suggests that the longitudinal abnormality in HOCM is not related solely to obstruction but rather to the basic molecular and architectural myocardial pathology, such as sarcomere dysfunction, myocardial fibrosis, fiber disarray, and abnormal microvasculature, which are unlikely to be altered by surgical myectomy.
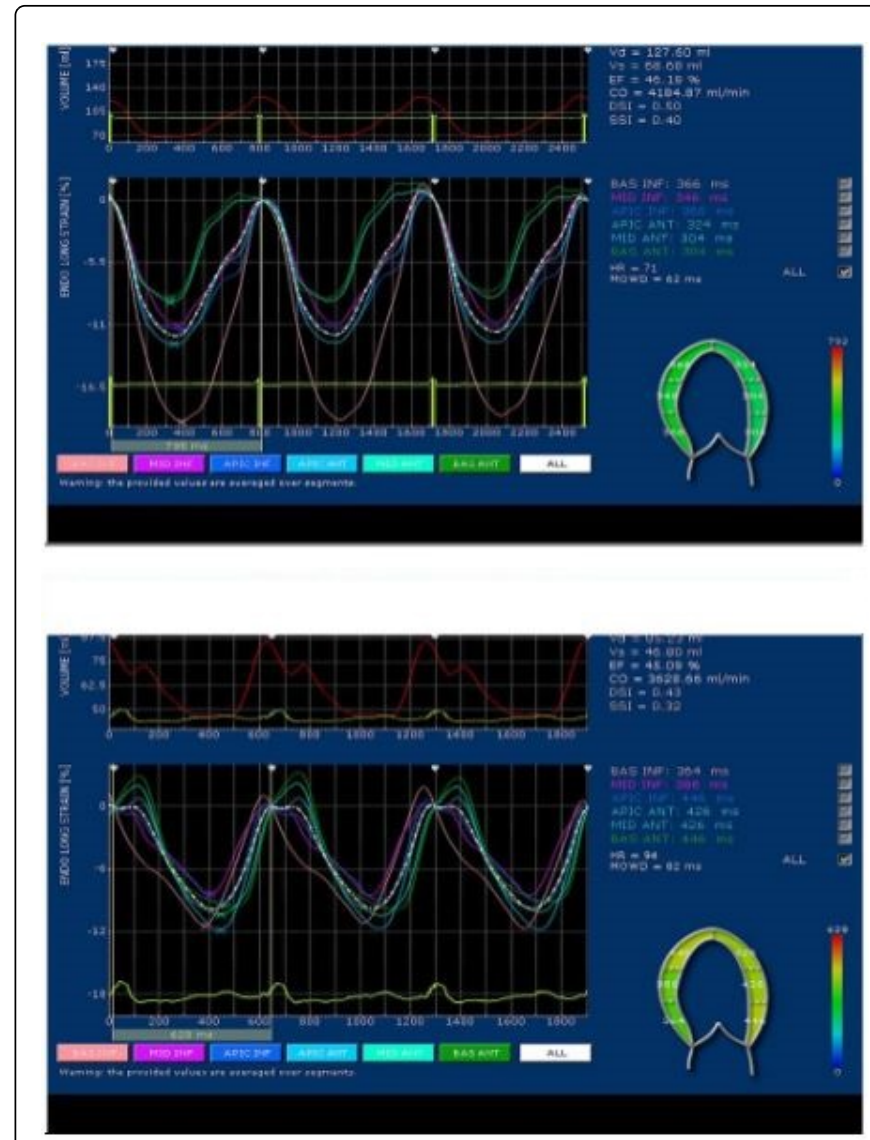

Figure 2: Longitudinal strain of anterior and inferior wall segments before (upper panel) and after (lower panel) surgical myectomy of the same patient.

In our study, we detected no significant improvement in LV dyssynchrony after surgical myectomy. The difference between our results and those obtained by Chen et al. may be due to the small sample size and short follow up period in our study (the main limitations of our study) or because Chen and colleagues used gated single photon emission computed tomography (SPECT) myocardial perfusion imaging (MPI), which is the most sensitive method for detecting LV synchronization [14]. Another limitation in our study is the absence of a gold standard method to detect the extent of myocardial fibrosis and disarray (cardiac magnetic resonance) and to compare the extent of myocardial involvement in each segment and its actual response to surgical myectomy. Future studies should consider these limitations in their design.

In symptomatic patients with severe AS, alleviating obstruction by valve replacement resulted in an increase in longitudinal strain to near normal values and normalization of compensatory increased circumferential strain and apical rotation [12].
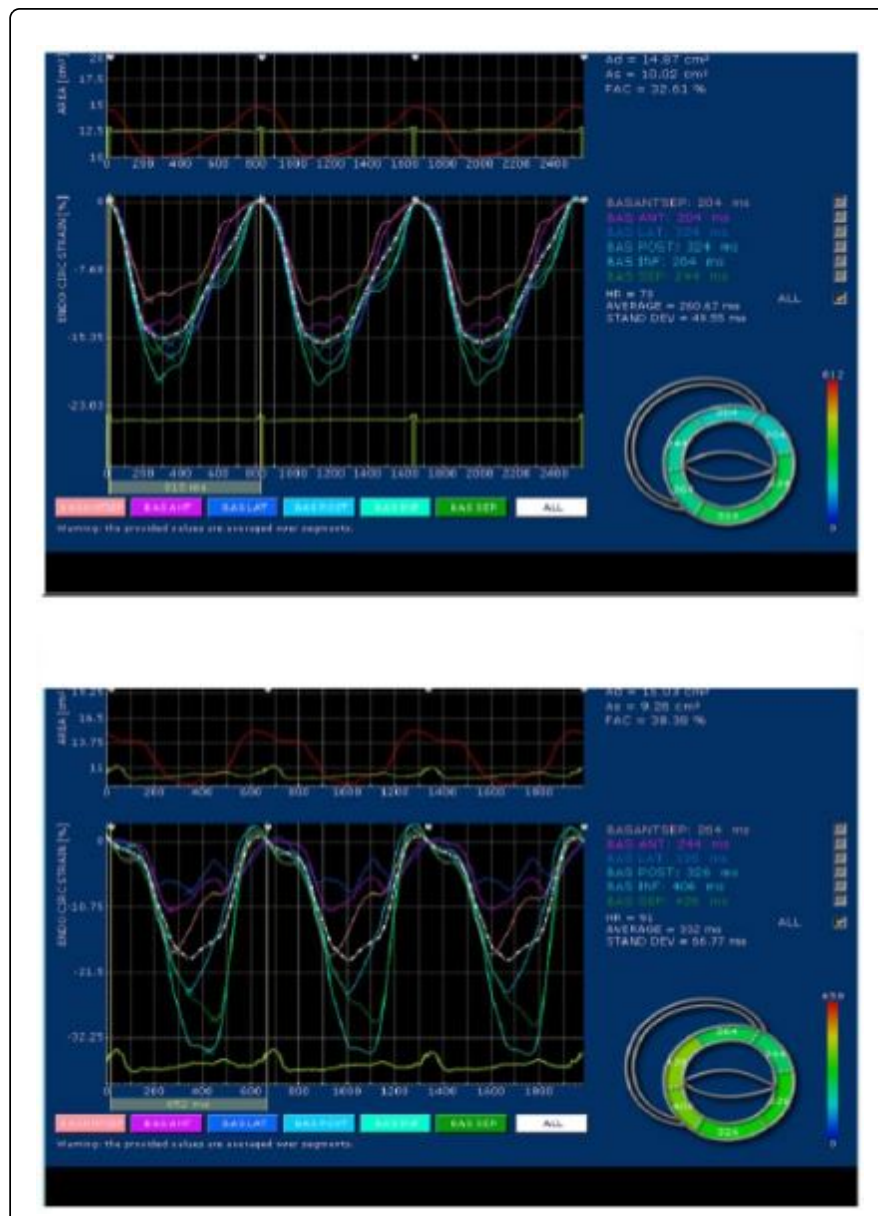

Figure 3: Circumferential strain at the level of basal LV (MV) segments before (upper panel) and after (lower panel) surgical myectomy of the same patient.

\begin{tabular}{|l|l|l|l|}
\hline Items & Pre Myectomy & Post Myectomy & p value \\
\hline TTP BS & $456.67 \pm 85.76$ & $472.80 \pm 70.36$ & 0.241 \\
\hline TTP MS & $408.33 \pm 79.03$ & $422.00 \pm 66.12$ & 0.115 \\
\hline TTP AS & $356.53 \pm 70.32$ & $405.66 \pm 68.39$ & 0.268 \\
\hline TTP Septum & $407.17 \pm 67.50$ & $433.48 \pm 59.87$ & 0.572 \\
\hline TTP BL & $384.13 \pm 79.19$ & $372.60 \pm 64.60$ & 0.298 \\
\hline TTP ML & $385.47 \pm 68.73$ & $358.93 \pm 56.39$ & 0.119 \\
\hline TTP AL & $347.00 \pm 62.21$ & $363.53 \pm 62.64$ & 0.712 \\
\hline TTP Lateral & $372.20 \pm 63.57$ & $365.02 \pm 45.30$ & 0.1 \\
\hline TTP BA & $378.40 \pm 70.61$ & $348.53 \pm 75.07$ & 0.234 \\
\hline TTP MA & $397.07 \pm 79.91$ & $374.86 \pm 70.08$ & 0.809 \\
\hline TTP AA & $378.80 \pm 75.39$ & $347.06 \pm 48.81$ & 0.455 \\
\hline TTP Anterior & $384.75 \pm 66.06$ & $356.82 \pm 50.27$ & 0.267 \\
\hline TTP BI & $396.20 \pm 76.69$ & $358.66 \pm 48.05$ & 0.901 \\
\hline
\end{tabular}


Citation: Abd-El-Kareem TS, Badran HM, Al-Amin AM, Ahmed NF (2019) The Effects of Surgical Myectomy on Left Ventricular Mechanics in Patients with Hypertrophic Obstructive Cardiomyopathy. J Cardiovasc Dis Diagn 7: 356. doi:10.4172/2329-9517.1000356

Page 6 of 7

\begin{tabular}{|l|l|l|l|}
\hline TTP MI & $384.80 \pm 64.37$ & $350.86 \pm 51.52$ & 0.757 \\
\hline TTP AI & $371.73 \pm 54.50$ & $356.40 \pm 73.16$ & 0.374 \\
\hline TTP Inferior & $384.24 \pm 53.06$ & $355.31 \pm 42.11$ & 0.507 \\
\hline TTP-SD & $58.59 \pm 13.68$ & $65.12 \pm 24.76$ & 0.499 \\
\hline TTP mean & $387.09 \pm 49.96$ & $377.66 \pm 26.80$ & 0.052 \\
\hline TTP Min & $306.47 \pm 34.37$ & $283.00 \pm 35.36$ & 0.01 \\
\hline TTP Max & $487.40 \pm 65.15$ & $490.66 \pm 57.48$ & 0.305 \\
\hline TTP-d & $180.93 \pm 45.81$ & $207.66 \pm 70.39$ & 0.238 \\
\hline
\end{tabular}

Note: Data are means \pm standard deviations.

Table 5: Compares time to peak (TTP) pre and post myectomy in enrolled patients.
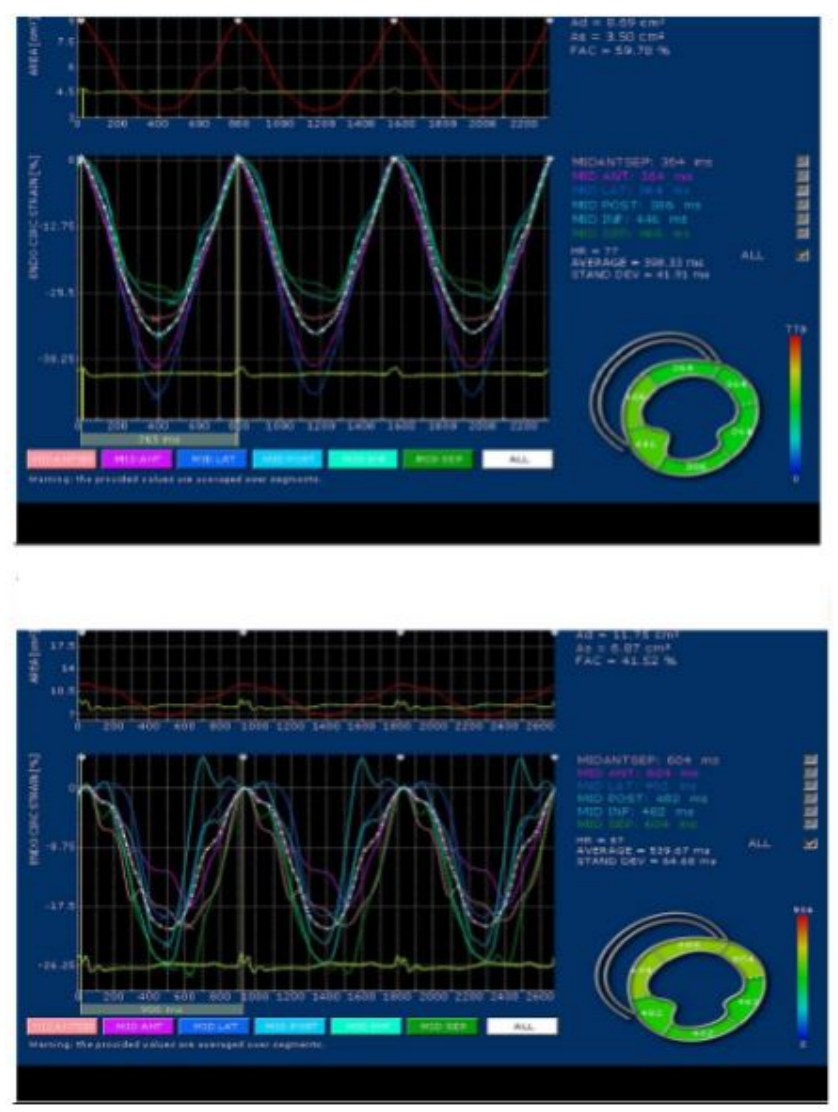

Figure 4: Circumferential strain at the level of Mid LV (PM) segments before (upper panel) and after (lower panel) surgical myectomy of the same patient.

We found that HOCM mechanics before and after myectomy were similar to severe AS mechanics before and after aortic valve replacement, but not identical. Compared to patients with severe symptomatic AS (before aortic valve replacement), the average longitudinal strain was not as low. This may be due to the higher outflow tract gradients and longer duration of fixed obstruction in

surgical AS patients as opposed to hypertrophic cardiomyopathy patients with dynamic obstruction.

\section{Conclusion}

Surgical myectomy improves symptoms, relieves LV outflow tract obstruction and decreases left atrial volume index in patients with HOCM. These changes differ somewhat from those in patients with AS undergoing valve replacement and provide insights to the different mechanical adaptation to chronic elevated afterload observed in HOCM. Future studies should employ a larger sample size and more sensitive methods of synchrony detection to further characterize the impact of myectomy on LV mechanisms in HOCM patients.

\section{Conflicts of Interest}

There are no conflicts of interest for the present study.

\section{References}

1. Nishimura RA, Holmes Jr DR (2004) Hypertrophic obstructive cardiomyopathy. N Engl J Med 350: 1320-1327.

2. Veselka J, Anavekar NS, Charron P (2017) Hypertrophic obstructive cardiomyopathy. Lancet 389: 1253-1267.

3. Davies M, Pomerance A, Teare R (1974) Pathological features of hypertrophic obstructive cardiomyopathy. J Clin Pathol 27: 529-535.

4. Wigle ED, Rakowski H, Kimball BP, Williams WG (1995) Hypertrophic cardiomyopathy: Clinical spectrum and treatment. Circulation 92: 1680-1692.

5. Seggewiss H, Gleichmann U, Faber L, Fassbender D, Schmidt HK, et al. (1998) Percutaneous transluminal septal myocardial ablation in hypertrophic obstructive cardiomyopathy: Acute results and 3-month follow-up in 25 patients. J Am Coll Cardiol 31: 252-258.

6. Nagueh SF, Ommen SR, Lakkis NM, Killip D, Zoghbi WA, et al. (2001) Comparison of ethanol septal reduction therapy with surgical myectomy for the treatment of hypertrophic obstructive cardiomyopathy. J Am Coll Cardiol 38: 1701-1706.

7. Jeanrenaud X, Goy JJ, Kappenberger L (1992) Effects of dual-chamber pacing in hypertrophic obstructive cardiomyopathy. Lancet 339: 1318-1323.

8. Smedira NG, Lytle BW, Lever HM, Rajeswaran J, Krishnaswamy G, et al. (2008) Current effectiveness and risks of isolated septal myectomy for hypertrophic obstructive cardiomyopathy. Ann Thorac Surg 85: 127-133.

9. Stuber M, Scheidegger MB, Fischer SE, Nagel E, Steinemann F, et al. (1999) Alterations in the local myocardial motion pattern in patients suffering from pressure overload due to aortic stenosis. Circulation 100: 361-368.

10. Elmaraezy A, Ismail A, Abushouk AI, Eltoomy M, Saad S, et al. (2017) Efficacy and safety of transcatheter aortic valve replacement in aortic stenosis patients at low to moderate surgical risk: A comprehensive metaanalysis. BMC Cardiovasc Disord 17: 234.

11. Moravsky G, Bruchal-Garbicz B, Jamorski M, Ralph-Edwards A, Gruner C, et al. (2013) Myocardial mechanical remodeling after septal myectomy for severe obstructive hypertrophic cardiomyopathy. J Am Soc Echocardiogr 26: 893-900.

12. Carasso S, Cohen O, Mutlak D, Adler Z, Lessick J, et al. (2011) Relation of myocardial mechanics in severe aortic stenosis to left ventricular ejection fraction and response to aortic valve replacement. Am J Cardiol 107: 1052-1057.

13. Faber L, Prinz C, Welge D, Hering D, Butz T, et al. (2011) Peak systolic longitudinal strain of the lateral left ventricular wall improves after septal ablation for symptomatic hypertrophic obstructive cardiomyopathy: A follow-up study using speckle tracking echocardiography. Int J Cardiovasc Imaging 27: 325-333. 
Citation: Abd-El-Kareem TS, Badran HM, Al-Amin AM, Ahmed NF (2019) The Effects of Surgical Myectomy on Left Ventricular Mechanics in Patients with Hypertrophic Obstructive Cardiomyopathy. J Cardiovasc Dis Diagn 7: 356. doi:10.4172/2329-9517.1000356

Page 7 of 7

14. Chen J, Nagaraj H, Bhambhani P, Kliner DE, Soman P, et al. (2012) Effect of alcohol septal ablation in patients with hypertrophic cardiomyopathy on left-ventricular mechanical dyssynchrony as assessed by phase analysis of gated SPECT myocardial perfusion imaging. Int J Cardiovasc Imaging 28: $1375-1384$ 